\title{
Sobre os sentidos do ensino de música na educação básica: uma discussão a partir da Lei $n^{\circ} 11.769 / 2008$
}

\author{
Luciana Del-Ben* \\ Universidade Federal do Rio Grande do Sul
}

\section{Resumo:}

Depois de vários anos, a música volta a ser conteúdo obrigatório nas escolas de ensino fundamental e médio, com a aprovação da Lei $n^{\circ} 11.769 / 2008$. Essa aprovação, obviamente, não encerrou as discussões e açōes que a área de educação musical vem empreendendo ao longo das últimas décadas. Ao contrário, parece ter mobilizado ainda mais diferentes pessoas envolvidas com o tema em questão. Diante do atual momento, o presente artigo busca discutir algumas das dimensões envolvidas no processo de implementação da Lei, quais sejam: a formação de professores, princípios e diretrizes subjacentes à elaboração de propostas de ensino; a complexidade dos processos de criação e implementação de políticas educacionais; e, por fim, as finalidades do ensino de música na educação básica.

Palavras-chave: música e escolarização; políticas e práticas educacionais; Lei $n^{\circ}$ $11.769 / 2008$

* Luciana Del-Ben é Doutora em Música pela Universidade Federal do Rio Grande do Sul (UFRGS), Professora do Departamento de Música e do Programa de Pós-Graduação em Música da UFRGS e Bolsista de Produtividade em Pesquisa Nível 2 do CNPq. 


\section{Sobre os sentidos do ensino de música na educação básica'}

Vivemos um momento importante para a educação musical brasileira. Depois de vários anos de luta da área, a música volta a ser conteúdo obrigatório nas escolas de ensino fundamental e médio, com a aprovação da Lei $n^{\circ} 11.769$. em 18 de agosto de 2008.

A aprovação da Lei, obviamente, não encerrou as discussões e ações que a área de educação musical vem empreendendo ao longo, pelo menos, das três últimas décadas. Ao contrário, parece ter mobilizado mais fortemente não só pesquisadores, formadores e professores de música, mas uma diversidade de pessoas, envolvidas, de diferentes formas e a partir de diferentes perspectivas, com o tema em questão.

O momento é propício não somente para definir estratégias, planejar ações e elaborar propostas tendo em vista o cumprimento da lei, mas, me parece, principalmente, pela oportunidade que representa - ou melhor, demanda - para refletirmos sobre a complexidade inerente às políticas e práticas no campo da educação musical e sobre os sentidos da música na educação básica. O propósito do presente artigo é contribuir com essa reflexão, partilhando idéias e experiências no sentido de discutir algumas das dimensões envolvidas no processo de implementação da Lei em questão.

\section{Da formação dos professores}

A complexidade do processo se revela já no momento da aprovação da Lei $n^{\circ}$ 11.769/2008: ao mesmo tempo em que era celebrada, essa aprovação gerou uma série de questionamentos, dúvidas e, também, preocupações e

\footnotetext{
1 Este texto toma como base idéias apresentadas e discutidas nos Encontros Regionais da Associação Brasileira de Educação Musical - Abem Sul, realizados em Blumenau/SC e Santa Maria/RS, respectivamente em 2007 e 2008; no XVII Congresso da Confederação de ArteEducadores do Brasil, realizado em Florianópolis/SC, em 2007; no Seminário Quero Educação Musical nas Escolas, realizado no Rio de Janeiro/RJ, em 2008; e no XVII Encontro Anual da Abem, realizado em 2008, em São Paulo.
} 
críticas, muitas delas veiculadas nos meios de comunicação. Parte dos questionamentos e dúvidas estava diretamente vinculada ao fato de ter sido vetado um dos artigos que constava no projeto da Lei: aquele que previa que o ensino de música deveria ser ministrado por professores com formação específica na área.

Foram apresentadas duas razões para o veto. A primeira delas é que pareceu ter gerado dúvidas, pois afirma que

no Brasil existem diversos profissionais atuantes nessa área [música] sem formação acadêmica ou oficial em música e que são reconhecidos nacionalmente. Esses profissionais estariam impossibilitados de ministrar tal conteúdo na maneira em que este dispositivo está proposto. (Mensagem $n^{\circ}$ 622, de 18 de agosto de 2008).

De fato, esses profissionais estão impossibilitados de ministrar aulas de música nas escolas de educação básica, ao menos como professores efetivos ou concursados. Isso porque a atual Lei de Diretrizes e Bases da Educação Nacional (LDB) - Lei $n^{\circ} 9.394 / 1996$ - é bastante clara no tocante à formação dos professores da educação básica. O Artigo 62, apresentado como parte do "TíTULO VI - Dos Profissionais da Educação", estabelece que:

Art. 62. A formação de docentes para atuar na educação básica far-se-á em nível superior, em curso de licenciatura, de graduação plena, em universidades e institutos superiores de educação, admitida, como formação mínima para o exercício do magistério na educação infantil e nas quatro primeiras séries do ensino fundamental, a oferecida em nível médio, na modalidade Normal.

A primeira parte do veto, portanto, contradiz a própria LDB. A formação em curso de licenciatura plena é exigida de todo e qualquer professor da educação básica, seja aquele que vai ensinar música, língua portuguesa, matemática ou qualquer outra área de conhecimento prevista na LDB. Como isso é explicitamente declarado no Artigo 62, não há necessidade de especificar a formação de professores de quaisquer áreas de conhecimento, disciplinas ou conteúdos específicos. Isso justifica a segunda parte do veto, onde se afirma que 
esta exigência [da formação específica na área de música] vai além da definição de uma diretriz curricular e estabelece, sem precedentes, uma formação específica para a transferência de um conteúdo. Note-se que não há qualquer exigência de formação específica para Matemática. Física, Biologia etc. Nem mesmo quando a Lei de Diretrizes e Bases da Educação Nacional define conteúdos mais específicos como os relacionados a diferentes culturas e etnias (art. 26, $\S 4^{\circ}$ ) e de língua estrangeira (art. 26, $\S$ $\left.5^{\circ}\right)$, ela estabelece qual seria a formação mínima daqueles que passariam a ministrar esses conteúdos. (Mensagem n 622, de 18 de agosto de 2008).

A exigência da licenciatura não é um mero capricho dos legisladores; ela reflete a preocupação com a profissionalização da docência e com a formação adequada daqueles que irão atuar num contexto específico - as escolas de educação básica. Como um exercício profissional específico, a docência na educação básica demanda a apropriação e a construção de um corpo também específico de conhecimentos, incluindo diversos tipos de saberes (ver Gauthier et al:, 1998; Pimenta, 1999; Tardif, 2002), aliado à compreensão do contexto de trabalho: a sala de aula, a instituição escolar e o sistema educacional e suas relações com os demais âmbitos da sociedade.

Um segundo conjunto de preocupações relacionadas à nova Lei refere-se à qualidade da formação dos professores, sugerindo que falta preparo aos professores de música, ou mesmo à ausência de pessoas qualificadas para dar aulas, aliada à escassez de materiais didáticos na área de música capazes de auxiliar ou orientar o trabalho dos docentes.

Com certeza, os cursos superiores deverão formar um maior número de professores licenciados em música para atender a demanda de todas as escolas de ensino fundamental e médio. Mas isso não significa que os atuais professores estejam despreparados ou mesmo que não existam professores qualificados para o ensino de música. A formação de professores de música é um tema que vem sendo amplamente debatido na área de educação musical, debate que tem acompanhado as principais tendências sobre formação de professores, tanto no Brasil quanto no exterior (ver, por exemplo, Bellochio, 2003; Del Ben, 2003; Mateiro, 2003; Souza, 2003; Pires, 2003; Cereser, 2004; Queiroz; Marinho, 2005; Hentschke; Azevedo; Araújo, 2006; Louro, 2008). A maioria dos cursos 
superiores de música abandonou, há vários anos, a concepção da chamada formação polivalente, que englobaria música, artes visuais e teatro, tanto que a expressão "Licenciatura em Educação Artística" vem seguida de uma habilitação específica, no nosso caso, a habilitação em música. Além disso, desde 2004, as Diretrizes Curriculares Nacionais para os Cursos de Graduação em Música reconhecem somente pelo nome Música qualquer graduação nessa área, seja licenciatura ou bacharelado (Conselho Nacional de Educação. Resolução CNE/CES 2/2004).

Os professores de música, portanto, vêm sendo preparados há vários anos para atuar nas escolas de educação básica. É claro que, como professores, sempre temos muito que aprender e aperfeiçoar, mas isso é próprio dessa profissão, que apresenta novos desafios a cada dia, já que lida com crianças, jovens e adultos em formação, vivendo num mundo em constante transformação e caracterizado pela acelerada produção de novos conhecimentos e tecnologias. Além disso, é preciso ter claro que a formação, por si só, não é suficiente para garantir a atuação profissional. Conforme argumenta Abreu (2008), com base na literatura da área de educação:

Para que se alcance a inserção ocupacional, não basta somente o título adquirido na universidade, mas, também relações sociais e institucionais, instâncias imprescindíveis para transformar formação em trabalho, pois. segündo Franzoi (2006), o conhecimento necessita da prática para se efetivar e concretizar as relações de trabalho. De modo semelhante, Weber (2000) acredita que atuar com profissionalismo exige do professor não só o domínio dos conhecimentos específicos, mas, também, a compreensão das questōes envolvidas em seu trabalho, como a de saber interagir cooperativamente com a comunidade profissional a que pertence bem como com a sociedade.

O professor, ao exercer sua profissão, precisa, segundo Imbernón (2001, p. 43), "concretamente daqueles aspectos profissionais de aprendizagem associados às instituicõos educativas como núcleos em que trabalha um conjunto de pessoas". Para Nóvoa (1995), o professor deverá se dar conta do que acontece no seu contexto de trabalho e provocar mudanças significativas no ensino e na realidade social a partir do domínio de saberes profissionais, uma vez que o sistema educacional deve dar respostas, as quais se encontram justificadas e mediatizadas pela linguagem técnica pedagógica. (Abreu, 2008, p. 4-5).

Quanto aos materiais didáticos na área de música, a crença de que são escassos ou até inexistentes pode ser facilmente revista se acessarmos a produção 
recente de diversos profissionais em diferentes partes do país, muitos deles vinculados às mesmas instituições de ensino superior que formam professores de música, entre elas, Universidade Federal do Rio Grande do Sul (UFRGS), Universidade do Estado de Santa Catarina (Udesc), Universidade Federal do Paraná (UFPR), Universidade Estadual Paulista (Unesp), Universidade Federal de Uberlândia (UFU) e Universidade Federal de Minas Gerais (UFMG), para citar somente algumas. Dentre essas produções, destaco o trabalho organizado por Souza (1997), intitulado Livros de música para a escola: uma bibliografia comentada, que identificou, em bibliotecas escolares, sebos e acervos particulares somente da cidade de Porto Alegre, 223 livros didáticos de música, publicados desde o início do século XX até a década de 1990. O acesso a esse material deve ser aperfeiçoado, assim como a produção atual, sem dúvida, deve ser constantemente ampliada, visando a atender a novas demandas educativomusicais, mas há vasto material à disposição dos professores de música.

Por outro lado, a preocupação com a suposta escassez de materiais didáticos pode estar relacionada à idéia de que os professores não seriam capazes de desenvolver suas práticas de ensino sem o auxílio desses materiais. Não se trata de questionar a importância dos materiais didáticos na/para a atuação dos professores, amplamente discutida pela literatura (ver, entre outros; Souza, 1997; Santos, 2001; Gonçalves; Costa, 2002; Silva, 2002; Garbosa, 2004; Oliveira, 2005; Souza; Del Ben, 2007; Souza et al., 2007), mas de refletir sobre como são concebidas e planejadas as práticas de ensino, tema de que trato a seguir.

\section{Da elaboração de propostas de ensino}

Acredito que uma das perguntas mais presentes ao longo do processo de discussão tanto do projeto da Lei quanto da própria Lei em tela tem sido: que práticas de ensino de música gostaríamos de ver nas escolas?

Num primeiro momento, talvez seja bastante tentador que as respostas a essa pergunta assumam a forma de um currículo, um programa ou até mesmo um modelo a ser adotado pelas escolas. Construídas a partir de nossas próprias 
perspectivas, essas respostas seriam muitas - e nem sempre convergentes porque muitas são as formas de desenvolver o ensino de música nas escolas, assim como diversos podem ser seus conteúdos e objetivos.

É possível que esse impulso por definir conteúdos, apresentar propostas curriculares ou escolher modelos de ensino tenha relação com a própria intermitência da música na legislação e nos currículos escolares, num desejo, talvez, de suprir a escassez de programas de ensino oficiais ou programas amplamente adotados e consolidados.

Ora, a existência de uma proposta oficial não garante que ela será adotada por todas as escolas e professores. Trago como exemplo os resultados do mapeamento que realizei junto a professores e diretores de escolas estaduais de educação básica de Porto Alegre (Del-Ben, 2005), onde somente 27,59\% dos 58 professores investigados afirmaram levar em consideração as recomendações e sugestões dos documentos curriculares elaborados pela Secretaria ou pelo Ministério de Educação para desenvolver suas práticas educativas. Mesmo o Canto Orfeônico conviveu com propostas de ensino paralelas, como nos mostram. por exemplo, pesquisas que analisaram a literatura e materiais didáticos correntes na década de 1930 (Souza, 1992; Garbosa, 2004).

Qualquer proposta de ensino, assim como qualquer material didático, será adotada, parcial ou integralmente, somente se fizer sentido para escolas e professores, se atender a seus objetivos e interesses e também a suas condições e necessidades. Além disso, as escolas e seus professores não precisam, necessariamente, de uma proposta definida por agentes externos a elas para que consigam desenvolver o ensino de música. Um indicativo disso é que, apesar de não ser componente curricular obrigatório, a música não desapareceu das escolas (ver Souza et al., 2002; Santos, 2005), como nos mostram diversos trabalhos realizados em diferentes partes do país. Os resultados do mapeamento junto a escolas estaduais de Porto Alegre, já mencionado, indicam que em 71,62\% dessas escolas havia algum tipo de atividade musical sendo desenvolvida (DelBen, 2005). De modo semelhante, o trabalho realizado por Hirsch (2007), junto a 139 professores de arte/música de 104 escolas estaduais de ensino fundamental 
e médio pertencentes à $5^{\text {a }}$ Coordenadoria Regional de Educação do Rio Grande do Sul, sediada em Pelotas, mostra que a música faz parte das práticas de 81,4\% dos professores investigados. Também na educação infantil é forte a presença da música: resultados de estudo realizado com 123 professoras unidocentes da Rede Municipal de Ensino de Porto Alegre indicam que "a música está presente nas práticas de 99,19\% das professoras" (Diniz; Del-Ben, 2006, p. 29).

É claro que podemos apontar problemas em relação ao que vem acontecendo nas escolas, como: a) o reduzido número de professores licenciados em música atuando em escolas públicas; b) o também reduzido número de escolas públicas que oferecem aulas de música como componente curricular; c) o caráter esporádico das atividades musicais; ou d), a manutenção do ensino de música vinculado à idéia de educação artística (ver, entre outros, Del-Ben, 2005).

Mas, apesar dos problemas, não há como negar a capacidade dos professores - e, vistos coletivamente, das escolas - de conceber e concretizar práticas diversas de educação musical, independentemente de prescrições da legislação ou de propostas oficiais.

Há mais de duas décadas, a literatura da área da educação tem sustentado a idéia do professor como protagonista dos processos educativos (Elbaz, 1981; Clandinin, 1985; Calderhead, 1987). Dizer que o professor não é um executor de currículos e materiais didáticos, mero transmissor de conteúdos ou técnico que aplica conhecimentos e propostas produzidas por outras pessoas, externas às escolas e salas de aula, tem sido prática corrente. Temos trabalhado a partir da concepção do professor como profissional com autonomia, capaz de analisar, interpretar, agir e refletir sobre as situaçōes com as quais têm de lidar. Como observa Gimeno Sacristán (1999, p. 100):

[...] todo professor, pelo fato de ser humano, dispõe de material cognitivo, possui "teorias", pensamentos sobre o que faz, sobre o que se pode e sobre o que é preciso fazer; possui crenças sobre suas práticas, elabora explicações sobre o que tem feito, o que continua fazendo e sobre os planos alternativos que é preciso desenvolver. 
O protagonismo e a autonomia de cada professor, no entanto, devem ser exercidos no âmbito de um projeto coletivo, construído pela escola, conforme indica a atual LDB. O Artigo 15 da LDB, por exemplo, dispõe que:

Art. 15. Os sistemas de ensino assegurarão às unidades escolares públicas de educação básica que os integram progressivos graus de autonomia pedagógica e administrativa e de gestão financeira, observadas as normas gerais de direito financeiro público (grifos meus).

O projeto pedagógico de cada escola, por sua vez, deve ser orientado pelo conjunto de princípios, fundamentos e procedimentos estabelecidos pelas Diretrizes Curriculares Nacionais, para a Educação Infantil, o Ensino Fundamental e o Ensino Médio. Retomo, aqui, algumas das Diretrizes Curriculares Nacionais para o Ensino Fundamental, em seu Artigo $3^{\circ}$ :

II - Ao definir suas propostas pedagógicas, as escolas deverão explicitar o reconhecimento da identidade pessoal de alunos, professores e outros profissionais e a identidade de cada unidade escolar e de seus respectivos sistemas de ensino.

III - As escolas deverão reconhecer que as aprendizagens são constituídas pela interação dos processos de conhecimento com os de linguagem e os afetivos, em conseqüência das relações entre as distintas identidades dos vários participantes do contexto escolarizado; as diversas experiências de vida de alunos, professores e demais participantes do ambiente escolar, [...] devem contribuir para a constituição de identidades afirmativas, persistentes e capazes de protagonizar ações autônomas e solidárias em relação a conhecimentos e valores indispensáveis à vida cidadã.

IV - Em todas as escolas deverá ser garantida a igualdade de acesso para alunos a uma base nacional comum, de maneira a legitimar a unidade e a qualidade da ação pedagógica na diversidade nacional. A base comum nacional e sua parte diversificada deverão integrar-se em torno do paradigma curricular, que vise a estabeleçer a relação entre a educação fundamental e:

a) a vida cidadã através da articulação entre vários dos seus aspectos como: [saúde; sexualidade; meio ambiente; entre outros]. E:

b) as áreas de conhecimento:

[entre elas, as Artes] (grifos meus). (Conselho Nacional de Educação. Resolução CNE/CEB 2/1998).

Em nenhum momento as Diretrizes estabelecem objetivos e conteúdo programático dos projetos pedagógicos, ou formatos e modelos a serem desenvolvidos pelas escolas. Ao contrário, enfatizam a idéia de identidade, seja 
dos participantes da comunidade escolar, seja da própria unidade escolar. Numa sociedade democrática como a nossa, caracterizada pela diversidade cultural, social, étnico-racial, política, religiosa, de gênero, de orientação sexual etc., as escolas parecem ser entendidas como coletivo de profissionais da educação, capazes de decidir, com o apoio da comunidade escolar, os rumos de suas próprias ações, considerando tanto as orientações legais, quanto suas próprias concepções, anseios, necessidades e interesses.

Reconhecer a autonomia das escolas e dos professores não é o mesmo que dizer que a responsabilidade pelos rumos da educação musical escolar thes é exclusiva. O que defendo é que não se trata de escolher ou definir propostas a serem desenvolvidas pelas escolas, mas de partilhar experiências, criar redes de cooperação e de informações, apresentar e discutir concepções e práticas, e, a meu ver, principalmente, refletir sobre princípios e diretrizes, visando a contribuir com as decisões a serem tomadas pelas escolas.

Há um amplo corpo de conhecimento acumulado pela área de educação musical que poderá nos auxiliar nesse processo - conhecimento esse construído por meio da experiência, de estudos, pesquisas e debates que vêm ocorrendo em diversos espaços e fóruns qualificados, como os encontros da Associação Brasileira de Educação Musical (Abem). Esse conhecimento acumulado nos fornece exemplos, experiências e também bases para pensar e concretizar a educação musical que queremos. Sem dúvida, ainda temos como desafio ampliar a comunicação e a circulação dessa produção coletiva, divulgando o conhecimento das várias teorias e práticas de educação musical que vêm sendo desenvolvidas no Brasil, o que poderá contribuir com o processo de implementação da Lei n 11.769/2008.

Por outro lado, o fato de contarmos com várias teorias e práticas de educação musical também suscita dúvidas em relação à eficácia ou ao alcance da nova legislação. Houve, de fato, alguma mudança? 


\section{Da criação e implementação das políticas educacionais}

No documento legal a mudança é muito sutil, não só pela extensão do parágrafo acrescentado ao Artigo 26 da LDB, que define as áreas ou conteúdos dos currículos escolares (o parágrafo $6^{\circ}$ ), quanto pelos termos que o compõem, conforme pode ser observado a seguir:

Art. 26. Os currículos do ensino fundamental e médio devem ter uma base nacional comum, a ser complementada, em cada sistema de ensino e estabelecimento escolar, por uma parte diversificada, exigida pelas características regionais e locais da sociedade, da cultura, da economia e da clientela.

$\S 1^{\circ}$ Os currículos a que se refere o caput devem abranger, obrigatoriamente. o estudo da língua portuguesa e da matemática, o conhecimento do mundo físico e natural e da realidade social e política, especialmente do Brasil.

$\S 2^{\circ} \mathrm{O}$ ensino da arte constituirá componente curricular obrigatório, nos diversos níveis da educação básica, de forma a promover o desenvolvimento cultural dos alunos.

[...]

§ 6을 A música deverá ser conteúdo obrigatório, mas não exclusivo, do componente curricular de que trata $\circ \S 2^{\circ}$ deste artigo. (Incluído pela Lei $n^{\circ}$ 11.769 , de 2008).

120 Portanto, no documento legal, não há qualquer garantia de que a música será componente curricular das escolas de ensino fundamental e médio. A única garantia parece ser a de que, em algum momento, a música deverá, obrigatoriamente, participar do processo de escolarização, o que não era explicitado anteriormente.

Em termos legais, no ensino de educação artística, conforme previa a legislação anterior - Lei $\mathrm{n}^{\circ}$ 5.692/1971 - estava implícita a presença do "conteúdo" música, já que a proposta era trabalhar de maneira integrada com artes plásticas, música e teatro. $\mathrm{A}$ atual LDB, antes da alteração dada pela Lei $\mathrm{n}^{\circ}$ 11.769/2008, previa somente a obrigatoriedade do ensino de arte, sem definição dos conteúdos obrigatórios dessa área. Esses conteúdos são apresentados nos referenciais e parâmetros curriculares para a educação infantil, o ensino fundamental e o ensino médio, elaborados pelo Ministério da Educação. Embora 
não sejam compulsórios, esses referenciais e parâmetros constituem umà orientação oficial para a prática pedagógica nas escolas (Penna, 2001). Nos Parâmetros Curriculares Nacionais para o ensino fundamental (PCN), por exemplo, a música é uma dentre as linguagens ou modalidades artísticas que constituem o componente curricular arte. As diferentes linguagens artísticas, entretanto, não são tratadas como componentes, disciplinas ou conteúdos específicos, mas como modalidades da grande área arte. Em função disso, a presença das diversas modalidades artísticas não é obrigatória em todo o currículo do ensino fundamental. Os PCN apenas recomendam que "o aluno, ao longo da escolaridade, tenha oportunidade de vivenciar o maior número de formas de arte" (Brasil, 1997, p. 55). A alteração proposta em 1996, conforme explicitado nos PCN, foi no sentido de substituir o ensino polivalente de artes pelo ensino de modalidades específicas, sem garantir a presença de uma ou outra modalidade.

A mudança trazida pela Lei $n^{\circ} 11.769 / 2008$, me parece, é mais simbólica ou política que operacional, pois o termo música passa a constar, explicitamente, na lei que rege o sistema educacional brasileiro. Acredito que, mesmo que de forma sutil, ou pouco definida, essa alteração poderá fortalecer, em longo prazo, a área de música como parte da formação básica dos alunos.

Por outro lado, seria ingênuo pensar que a legislação, por si só, seria suficiente para transformar as práticas educativas nas escolas. O processo de implementação de leis ou de políticas educacionais é bastante complexo, como nos mostram diferentes perspectivas encontradas na literatura. Um exemplo é a abordagem do ciclo de políticas, elaborada pelos ingleses Stephen Ball e Richard Bowe e colaboradores. Conforme explica Mainardes (2006, p. 50), para esses autores

o foco da análise de políticas deveria incidir sobre a formação do discurso da política e sobre a interpretação ativa que os profissionais que atuam no contexto da prática fazem para relacionar os textos da política à prática. Isso envolve identificar processos de resistência, acomodações, subterfúgios e conformismo dentro e entre as arenas da prática, e o delineamento de conflitos e disparidades entre os discursos nessas arenas. 
A proposta da abordagem é compreender esse processo como um ciclo contínuo constituído por três contextos principais e inter-relacionados: o contexto de influência, o contexto da produção de texto e o contexto da prática. 0 primeiro contexto é aquele onde são construídos as políticas e os discursos políticos. Mainardes esclarece que:

É nesse contexto que grupos de interesse disputam para influenciar a definição das finalidades sociais da educação e do que significa ser educado. Atuam nesse contexto as redes sociais dentro e em torno de partidos políticos, do governo e do processo legislativo. É também nesse contexto que os conceitos adquirem legitimidade e formam um discurso de base para a política. (2006, p. 51).

O contexto de influência está intimamente relacionado com o contexto da produção de texto, embora essa não seja uma relação direta ou linear:

Os textos políticos [...] representam a política. Essas representações podem tomar várias formas: textos legais oficiais e textos políticos, comentários formais ou informais sobre os textos oficiais, pronunciamentos oficiais, vídeos etc. Tais textos não são, necessariamente, internamente coerentes e claros, e podem também ser contraditórios. Eles podem usar os termoschave de modo diverso. [...] Os textos políticos são o resultado de disputas e acordos, pois os grupos que atuam dentro dos diferentes lugares da produção de textos competem para controlar as representações da política (Bowe et al., 1992). Assim, políticas são intervenções textuais, mas elas também carregam limitações materiais e possibilidades. (2006, p. 52).

Por fim, o contexto da prática é aquele onde

a política está sujeita à interpretação e recriação e onde a política produz efeitos e conseqüências que podem representar mudanças e transformações significativas na política original. Para estes autores, o ponto-chave é que as políticas não são simplesmente "implementadas" dentro desta arena (contexto da prática), mas estão sujeitas à interpretação e, então, a serem "recriadas". (2006, p. 53).

Como enfatiza Mainardes (p. 53), na abordagem do ciclo de políticas "os professores e demais profissionais exercem um papel ativo no processo de interpretação e reinterpretação das políticas educacionais e, dessa forma, o que 
eles pensam e no que acreditam têm implicaçōes para o processo de implementação das políticas".

Mainardes esclarece ainda que, posteriormente à definição desses três contextos, os autores acrescentam outros dois: o contexto dos resultados ou efeitos das políticas, que "preocupa-se com questões de justiça, igualdade e liberdade individual" (p. 54), e o contexto de estratégia política, que "envolve a identificação de um conjunto de atividades sociais e políticas que seriam necessárias para lidar com as desigualdades criadas ou reproduzidas pela política investigada" (p. 55).

As políticas, portanto, assim como a legislação delas resultantes, não são "um texto fixo ou rígido" (Smit, 2005, p. 299). Elas são “contestadas e debatidas a partir de pontos de vista contrastantes e opostos, o que, em si, pode impedir o processo de implementação" (p. 299).

Weaver-Hightower (2008) concebe a criação e implementação das políticas como um processo ainda mais complexo. O autor propõe que as políticas sejam analisadas a partir de uma perspectiva ecológica:

Uma ecologia política [policy ecology] consiste na política em si e todos os textos, histórias, pessoas, lugares, grupos, tradições, condições econômicas e políticas, instituições e relações que afetam a política ou que são afetados por ela. Cada fator contextual e cada pessoa que contribui com, ou é influenciado por, uma política, em qualquer nível, tanto antes quanto depois de sua criação e implementação, é parte de uma ecologia complexa (2008, p. 155).

Essa ecologia, portanto, inclui não somente políticos, escolas e professores, mas meios de comunicação, grupos de pais ou editoras, e todas as "outras pessoas e instituições que permitem que o processo funcione, não importando quão insignificante sua função possa parecer à primeira vista" (2008, p. 155).

Essas, dentre outras perspectivas possíveis, talvez nos ajudem a compreender porque, apesar da elaboração de políticas e legislações e da produção crescente da área de educação musical no Brasil, ainda sejam freqüentes dúvidas, questionamentos e críticas, por parte de diversas pessoas e 
instituições envolvidas com a educação musical, tanto sobre quem deve ou pode ensinar música nas escolas de educação básica e sobre os possíveis formatos das práticas educativo-musicais a serem nelas desenvolvidas - como já discutido neste trabalho -, quanto sobre a "situação" da educação musical no Brasil, mais especificamente sobre a presença/ausência da música nas escolas.

\section{Das finalidades do ensino de música na educação básica}

No texto que inicia os anais do I Encontro Anual da Associação Brasileira de Educação Musical (Abem), realizado em 1992, no Rio de Janeiro, Tacuchian (1992) sugere que um dos objetivos desse Encontro seria buscar soluções para o que ele chamou de "grande mistério" (1992, p. 6) da área de educação musical, e que tomava corpo naquele último quarto de século. Esse mistério, de modo resumido, parecia constituir-se do seguinte modo:

a. ações educativas em música sempre foram desenvolvidas nos mais diversos espaços da sociedade (na escola, na comunidade, em espaços mais ou menos formais), com ênfases e objetivos também

124 diversos:

b. vários documentos foram elaborados coletivamente em encontros nacionais e internacionais, sugerindo, defendendo ou criticando concepções, perspectivas teóricas e metodológicas e aspectos legais. A legislação educacional, e mesmo as nomenclaturas utilizadas para conceituar nossas práticas de ensino - "canto orfeônico, canto em conjunto, educação musical, educação artística, educação através da arte, educação estética" (1992, p. 7), entre outros - também foram postas em cheque ao longo dos anos;

c. diversos recursos, estratégias e princípios orientadores de nossas ações educativas também foram discutidos, assim como possíveis finalidades da educação musical, seja "conhecimento, lazer cultural, desenvolvimento criativo da personalidade, integração com a realidade 
cultural [...], preservação das raízes do passado, criação de público" (1992, p. 8) ou a afirmação de uma suposta cultura nacional.

Como afirma Tacuchian,

todos esses caminhos tiveram sua época de esplendor e seus advogados mais ou menos ardentes. [...] Apesar de tantos remédios miraculosos, tantos documentos bem redigidos e assinados pelos maiores mestres de cada época, apesar dos choques heterodoxos, a Educação Musical apresentou um irremediável declínio [naqueles] últimos 25 anos e não se [encontrava, naquela época - 1992], em bom estado de saúde. Qual seria a razão desta doença? Por que nenhum caminho apontado conseguiu curar a combalida Educação Musical no Brasil? (p. 8).

Embora muitos de nós possamos concordar com o posicionamento do autor, talvez seja relevante questionar: por que falar em declínio, ou mesmo em doença, se tantas idéias foram discutidas e várias propostas e legislaçōes foram elaboradas, desenvolvidas e transformadas?

Mais de 10 anos depois, Penna (2004, p. 8) observa que:

Desde a década de 1970 não há garantias formais para o ensino de música - em sua especificidade - na educação básica. No entanto, de acordo com as leis educacionais e os diversos termos normativos correlatos, a música integra, potencialmente, o campo da arte - ou seja, a música é uma dentre outras linguagens que podem ser trabalhadas na escola pelo componente curricular da arte. No caso da Educação Artística, implantada pela Lei $5692 / 71$, a música é uma das habilitações da licenciatura plena, ao lado de artes cênicas, artes plásticas e desenho. Já nos Parâmetros Curriculares Nacionais (Brasil, 1997; 1998; 1999), são propostas diversas modalidades artísticas para a matéria escolar Arte: artes visuais, teatro, dança e música e ainda artes audiovisuais, no ensino médio. Nesse sentido, apesar de algumas mudanças, há uma continuidade nos dispositivos legais das décadas de 1970 e de 1990, sendo que, como conteúdo curricular potencial, à realização efetiva da música na prática escolar concreta depende de inúmeros fatores, inclusive do modo como atuamos na prática cotidiana, nos múltiplos espaços possíveis.

A autora prossegue, afirmando que, "mesmo sem garantias legais específicas, há possibilidades que a educação musical não tem conseguido realizar" (Penna, 2004, p. 11 - grifos da autora) nas escolas. Em um trabalho anterior, essa autora já questionava 
até que ponto a reduzida presença da música na educação básica não reflete o fato de que a educação musical reluta em reconhecer a escola regular de ensino fundamental [ou, de modo mais amplo, a escola de educação básica] como um espaco de trabalho seu? Um espaço de trabalho que deve ser conquistado pelo compromisso com os objetivos de formação geral e de democratização da cultura, assim como pela busca de propostas pedagógicas e metodológicas adequadas para esse contexto escolar e a sua clientela. (Penna, 2002, p. 17 - grifos da autora).

Se há possibilidades que a educação musical não tem conseguido realizar" (Penna, 2004, p. 11), quais são aquelas que ela tem conseguido realizar? Seriam essas as propostas adequadas para o contexto escolar? Nosso foco de atenção tem se voltado para as possibilidades a realizar ou para as possibilidades realizadas? Para o que ainda não existe ou para o que existe? Quais seriam nossas representações sobre o ensino de música nas escolas que nos levam a concluir pela "reduzida presença da música na educação básica" (Penna, 2002. p. 17) ou pelo precário estado de saúde da educação musical (Tacuchian, 1992), se estudos nos indicam que a música não saiu das escolas (Souza et al., 2002; Santos, 2005)? Tomamos música e ensino de música como sinônimos? Quais seriam as relações entre, de um lado, a relutância da área em reconhecer a escola como um espaço de trabalho seu (Penna, 2002), e, de outro, nossas representações sobre a educação básica?

Como ainda nos faltam trabalhos que nos auxiliem a buscar respostas para essa última questão, recorro à minha experiência. Como professora de um curso de licenciatura em música, venho percebendo que alguns licenciandos, futuros professores de música, ingressam no curso sem qualquer interesse ou desejo de atuar como professores de escolas de educação básica. Vários optam, antes mesmo do ingresso na licenciatura, pela atuação em escolas específicas de música, possivelmente porque, nesses espaços, se reconhecem fazendo e ensinando música, como observado por Santos (2005). Outros trazem idéias negativas da escola de educação básica, como sendo um espaço que não oferece condições adequadas de trabalho, pois faltam recursos para o ensino de música, as turmas são muito numerosas e a carga horária é reduzida. Algumas dessas idéias parecem ter sido construídas a partir de suas próprias experiências como 
alunos, caracterizadas por aulas de música onde não se fazia música, ao contrário de outros espaços onde puderam aprofundar sua formação musical, como aulas particulares ou escolas específicas de música. Por outro lado, muitos alunos sequer tiveram aulas de música ao longo da escolarização na educação básica. Há ainda aqueles que se referem à escola, especificamente à escola pública, como um ambiente de relaçốes humanas complexas ou mesmo conflituosas, onde se exige do professor uma série de tarefas para as quais ele não foi preparado, muito além de ensinar os "conteúdos" de sua área.

A essa experiência, contraponho os resultados de diversos trabalhos que buscam uma aproximação às realidades escolares, procurando compreender o que pensam e fazem professores, diretores, alunos ou pais, e às várias funções atribuídas à música nas escolas. Parte da comunidade escolar, principalmente os alunos, atribui à música a função de formar profissionais na área, tanto músicos quanto professores, como identificou Puerari (2006) ao investigar as funções da música para a comunidade da Escola Municipal de Ensino Fundamental Heitor VillaLobos, em Porto Alegre, que possui uma orquestra de flautas, há quase duas décadas, além de várias oficinas de ensino de instrumentos como projeto extracurricular.

Mas também temos aprendido com diferentes trabalhos que, muito além de desenvolver o domínio de conteúdos e habilidades musicais, os vários participantes da comunidade escolar esperam que a música cumpra as funções de transmissão de valores e tradições socioculturais; integração e cooperação entre as pessoas; desenvolvimento psicológico, motor e de capacidades cognitivas gerais; auxiliar na apropriação de conteúdos de outras disciplinas curriculares; acesso aos modos de vida de diferentes grupos socioculturais; desenvolvimento do respeito às diferenças e de valores e práticas democráticas; enfim, que a música contribua para o desenvolvimento global dos alunos como seres humanos e membros da sociedade (ver, por exemplo, Del Ben, 2001; Souza et al., 2002; Hummes, 2004; Pedrini, 2006).

As funções atribuídas à música pela comunidade escolar parecem tomar como base suas experiências, crenças e conceitos, além de anseios e necessidades próprias, não só em relação à música, mas também em relação à 
escolarização básica, cujos objetivos e funções ultrapassam o domínio de conhecimentos específicos. Conforme disposto na Lei de Diretrizes e Bases da Educação Nacional (Lei nº 9.394/96):

Art. 22. A educação básica tem por finalidades desenvolver o educando, assegurar-lhe a formação comum indispensável para o exercício da cidadania e fornecer-lhe meios para progredir no trabalho e em estudos posteriores.

Mais especificamente:

Art. 29. A educação infantil, primeira etapa da educação básica, tem como finalidade o desenvolvimento integral da criança até seis anos de idade, em seus aspectos físico, psicológico, intelectual e social, complementando a ação da família e da comunidade

[...]

Art. 32. O ensino fundamental obrigatório [...] terá por objetivo a formação básica do cidadão, mediante:

I - o desenvolvimento da capacidade de aprender, tendo como meios básicos o pleno domínio da leitura, da escrita e do cálculo;

II - a compreensão do ambiente natural e social, do sistema político, da tecnologia, das artes e dos valores em que se fundamenta a sociedade;

III - o desenvolvimento da capacidade de aprendizagem, tendo em vista a aquisição de conhecimentos e habilidades e a formação de atitudes e valores;

IV - o fortalecimento dos vínculos de família, dos laços de solidariedade humana e de tolerância recíproca em que se assenta a vida social.

[...]

Art. 35. O ensino médio [...] terá como finalidades:

I - a consolidação e o aprofundamento dos conhecimentos adquiridos no ensino fundamental, possibilitando o prosseguimento de estudos;

II - a preparação básica para o trabalho e a cidadania do educando, para continuar aprendendo, de modo a ser capaz de se adaptar com flexibilidade a novas condições de ocupação ou aperfeiçoamento posteriores;

III - o aprimoramento do educando como pessoa humana, incluindo a formação ética e o desenvolvimento da autonomia intelectual e do pensamento crítico;

IV - a compreensão dos fundamentos científico-tecnológicos dos processos produtivos, relacionando a teoria com a prática, no ensino de cada disciplina.

Apesar de todas essas finalidades bastante amplas, ainda é comum a idéia de que o ensino de música nas escolas não deveria servir a outros propósitos que não a própria música, o que quer que isso signifique, sendo que sua função 
seria a de propiciar o domínio progressivo de conteúdos chamados "musicais". Nesse caso, objetivos, conteúdos e atividades que constituem planos e práticas de ensino contemplariam apenas conceitos, procedimentos e elementos que poderíamos chamar de conteúdos sonoro-musicais - aqueles que se referem aos aspectos sonoros da música, suas propriedades e suas diferentes formas de relação e organização (ver Swanwick, 1979) -, como altura, duração, intensidade, timbre, expressão, a organização e estruturação desses mesmos elementos, além de história da música e análise musical. Seriam considerados secundários oú externos à área de música (portanto, extramusicais) aqueles termos que expressam finalidades da educação básica para além da aquisição de habilidades e conhecimentos específicos, como exercício da cidadania, desenvolvimento integral, formação de atitudes e valores, laços de solidariedade humana e formação ética, conforme especifica a Lei n 9.394/1996.

Sem dúvida, toda vivência musical - e a vivência é essencial para se ensinar e aprender música - envolve a experiência de aspectos sonoros. Não há como, nem porque, abrir mão deles. Por outro lado, música é sempre algo a ser vivenciado, ou seja, não existe música se não houver pessoas se relacionando com música, quaisquer que sejam as formas que essa relação assuma. E aquele que se relaciona com música não é um sujeito isolado, sem vínculos, sem história, sem identidades. Aquilo que ouço, componho, toco, sinto, penso sobre música, e a partir dela, é construído coletivamente, tanto a partir das pessoas que me estão mais próximas, quanto daquelas mais distantes e também daquelas que sequer tenho a chance de conhecer pessoalmente (ver Schutz, 1979).

Por outro lado, não podemos perder de vista que, por estar inserida em contextos escolares, as práticas que configuram o ensino de música constituem-se a partir de um projeto coletivo, ao mesmo tempo em que ajudam a constituí-lo. Esse projeto coletivo, de forma implícita ou explícita, visa a preparar os alunos para atuar no mundo (ver Gimeno Sacristán, 1998). É um projeto globalizador, 
que agrupa diversas facetas da cultura, do desenvolvimento pessoal e social, das necessidades vitais dos indivíduos para seu desempenho em sociedade, aptidões e habilidades consideradas fundamentais, etc. (Gimeno Sacristán, 1998, p. 55).

A escola é um espaço de ensino e de aprendizagem de muitos saberes, além dos sonoro-musicais, e parece que é isso que os vários participantes da comunidade escolar esperam do ensino de música, como sugerem os resultados das pesquisas antes mencionadas.

\section{À guisa de conclusão}

Parece claro que não há como conceber o ensino de música, quaisquer que sejam seus formatos, objetivos ou finalidades, sem música, isto é, sem que professores e alunos se relacionem com música. Por outro lado, entender e acolher as várias funções que a comunidade escolar atribui à música talvez nos auxilie a reconhecer as possibilidades que a educação musical tem conseguido realizar nas escolas e a refletir sobre formas consideradas legítimas, ou já

130 legitimadas, de ensinar e de aprender música, por pessoas diretamente envolvidas na/com a escolarização.

Nesse sentido, talvez, um diálogo mais profundo com a pedagogia possa nos ajudar a melhor compreender as características e finalidades da educação básica para que, assim, possamos, de fato, entender o que significa ensinar música na educação básica, que, como seus termos indicam, não é um espaço de especialização ou profissionalização em nenhuma das áreas de conhecimento. Portanto, pensar sobre os sentidos da música na educação básica envolve, necessariamente, refletir sobre processos de escolarização. E escolarizar a música, ou submetê-la ao processo de escolarização na educação básica, como propõe a Lei n 11.769/2008, não é torná-la menos música ou menos musical. É somente pensá-la de uma forma específica, para um contexto também específico. Escolarizar, como nos explica o Dicionário Aurélio, é "verbo transitivo direto e pronominal", que significa "submeter (-se) ao ensino escolar". Escolar é adjetivo 
de dois gêneros: "1. Relativo à escola [...]. 2. Próprio para ser usado em escola, no ensino [...]. 3. Próprio para se freqüentar a escola [...]. 4. Destinado especialmente às escolas [...]".

\section{Referências}

ABREU, D. V. Educação básica: campo de atuação profissional em música. In: ENCONTRO ANUAL DA ASSOCIAÇÃO BRASILEIRA DE EDUCAÇÃO MUSICAL, 17., 2008, São Paulo. Anais... São Paulo: Abem, 2008. p. 1-8. 1 CD.

BELLOCHIO, C. A formação profissional do educador musical: algumas apostas. Revista da ABEM, n. 8, p. 17-24, mar. 2003.

BRASIL. Ministério da Educação. Parâmetros curriculares nacionais: arte ( $1^{\circ}$ e $2^{\circ}$ ciclos). Brasília: MEC/SEF, 1997.

CALDERHEAD, J. Introduction. In: CALDERHEAD, J. (Ed.). Exploring teachers' thinking. London: Cassel, 1987. p. 1-19.

CERESER, C. M. I. A formação inicial de professores de música sob a perspectiva dos licenciandos: o espaço escolar. Revista da ABEM, n. 11, p. 27-36, set. 2004.

CLANDININ, D. J. Personal practical knowledge: a study of teachers' classroom images. Curriculum Inquiry, vol. 15, n. 4, 1985, p. 361-385.

Conselho Nacional de Educação. Câmara de Educação Básica. Resolução CNE/CEB 2/1998. Institui as Diretrizes Curriculares Nacionais para o Ensino Fundamental. Diário Oficial da União, Brasília: Seção 1, p. 31, 15 abr. 1998.

Conselho Nacional de Educação. Câmara de Educação Superior. Resolução CNE/CES 2/2004. Aprova as Diretrizes Curriculares Nacionais do Curso de Graduação em Música e dá outras providências. Diário Oficial da União, Brasília: Seção 1, p. 10, 12 mar. 2004.

DEL BEN, L. Concepções e ações de educação musical escolar: três estudos de caso. Porto Alegre, 2001a. Tese (Doutorado em Música), Instituto de Artes, Universidade Federal do Rio Grande do Sul.

- Múltiplos espaços, multidimensionalidade, conjunto de saberes: idéias para pensarmos a formação de professores de música. Revista da ABEM, n. 8, p. 29-32, mar. 2001.

L. Um estudo com escolas e professores da rede estadual de educação básica de Porto Alegre/RS: subsídios para a elaboração de políticas de educação musical. Relatório Técnico-Científico. Processo CNPq n 474146/03-0. 2005.

DINIZ, L. N.; DEL-BEN, L. Música na educação infantil: um mapeamento das práticas e necessidades de professoras da rede municipal de ensino de Porto Alegre. Revista da ABEM, Porto Alegre, n. 15, p. 27-37, set. 2006.

ELBAZ, F. The teacher's practical knowledge: report of a case study. Curriculum Inquiry, vol. 11, n. 1, 1981, p. 43-71. 
FERREIRA, A. B. de H. Novo Dicionário Eletrônico Aurélio. Versão 5.0. São Paulo: Positivo, 2004.

GARBOSA, L. Es tönen die Lieder... um olhar sobre o ensino de música nas escolas teutobrasileiras da década de 1930 a partir de dois cancioneiros selecionados. Revista da Abem, v. 10, p. 89-98, mar. 2004.

GAUTHIER, C. et al. Por uma teoria da pedagogia: pesquisas contemporâneas sobre o saber docente. Trad. de Francisco Pereira. ljuí: Editora UNIJUí, 1998.

GONÇALVES, L. N.; COSTA, M. C. L. S. O projeto conteúdos de música em livros didáticos: resultados parciais. In: ENCONTRO ANUAL DA ASSOCIAÇÃO BRASILEIRA DE EDUCAÇÃO MUSICAL, 11., Natal, 2002. Anais... Natal: ABEM, 2002. p. 393-402. 1 CD.

GIMENO SACRISTÁN. J. Poderes instáveis em educação. Porto Alegre: Artes Médicas Sul, 1999.

. O currículo: uma reflexão sobre a prática. Tradução de Ernani F. da Fonseca Rosa. 3 ed. Porto Alegre: Artes Médicas Sul, 1998.

HENTSCHKE, L; AZEVEDO, M. C. C. C.; ARAÚJO, R. C. Os saberes docentes na formação do professor: perspectivas teóricas para a educação musical. Revista da ABEM, n. 15, p. 4958, set. 2006.

HIRSCH, I. B. Música nas séries finais do ensino fundamental e no ensino médio: um survey com professores de arte/música de escolas estaduais da região sul do Rio Grande do Sul. Porto Alegre, 2007. Dissertação (Mestrado em Música), Instituto de Artes, Universidade Federal do Rio Grande do Sul.

HUMMES, J. M. As funções da música sob a ótica das direções escolares. Porto Alegre. 2004. Dissertação (Mestrado em música), Instituto de Artes, Universidade Federal do Rio Grande do Sul.

132 Lei n 9.394, de 20 de Dezembro de 1996. Estabelece as diretrizes e bases da educação nacional. Diário Oficial da União, Brasília: 23 dez. 1996.

Lei $n^{\circ} 11.769$, de 18 de Agosto de 2008. Altera a Lei $n^{\circ}$ 9.394, de 20 de dezembro de 1996, Lei de Diretrizes e Bases da Educação, para dispor sobre a obrigatoriedade do ensino da música na educação básica. Diário Oficial da União, Brasília: 19 ago. 2008.

LOURO, A. L. M. Cartas de licenciandos em música: (re)contando o vivido para centrar a aula no aluno. Revista da ABEM, n. 8, p. 63-68, set. 2008.

MATEIRO, T. A. N. O comprometimento reflexivo na formação docente. Revista da ABEM, n. 8, p. 33-38, mar. 2003.

Mensagem $\mathrm{n}^{\circ}$ 622, de 18 de agosto de 2008. Mensagem de veto. Disponível em: http://www.planalto.gov.br/CCIVIL_03/_Ato2007-2010/2008/Msg/VEP-622-08.htm). Acesso em: 07 out. 2008.

MAINARDES, J. Abordagem do ciclo de políticas: Uma contribuição para a análise de políticas educacionais. Educação \& Sociedade, vol. 27, n. 94, p. 47-69, jan./abr. 2006.

OLIVEIRA, F. de A. Materiais Didáticos nas aulas de música: um survey com professoras da Rede Municipal de Ensino de Porto Alegre. Porto Alegre, 2005. Dissertação (Mestrado em Música), Programa de Pós-Graduação em Música, Instituto de Artes, Universidade Federal do Rio Grande do Sul. 
PEDRINI. J. R. Concepçôes de aula de música no ensino fundamental: um estudo com mães de alunos. Porto Alegre, 2005. Trabalho de Conclusão de Curso (Graduação em Música), Instituto de Artes, Universidade Federal do Rio Grande do Sul.

PENNA, M. A dupla dimensão da política educacional e a música na escola: II - da legislação à prática escolar. Revista da ABEM, Porto Alegre, v. 11, p. 07-16, set. 2004.

Professores de música nas escolas públicas de ensino fundamental e médio: uma ausência significativa. Revista da ABEM, Porto Alegre, v. 7, p. 07-19, set. 2002.

Este é o ensino de artes que queremos? Uma análise das propostas dos Parâmetros Curriculares Nacionais. João Pessoa: Editora Universitária UFPB, 2001.

PIMENTA, S. G. (Org.). Saberes pedagógicos e atividade docente. São Paulo: Cortez, 1999.

PIRES, N. A identidade das licenciaturas na área de música: multiplicidade e hierarquia. Revista da ABEM, n. 9, p. 81-88, set. 2003.

PUERARI. M. A "Orquestra de flautas" da Escola Municipal de Ensino Fundamental Heitor Villa-Lobos: um estudo de suas funções para a comunidade escolar. Porto Alegre, 2005. Trabalho de Conclusão de Curso (Graduação em Música), Instituto de Artes, Universidade Federal do Rio Grande do Sul.

QUEIROZ, L. R.; MARINHO, V. M. Novas perspectivas para a formação de professores de música: reflexões acerca do Projeto Político Pedagógico da Licenciatura em Música da Universidade Federal da Paraíba. Revista da ABEM, n. 13, p. 83-92, set. 2005.

SANTOS, M. C. dos. Texto didático: propriedades textuais e pressupostos epistemológicos. Caxias do Sul: EDUCS, 2001. p 15-16.

SANTOS, R. M. S. Música, a realidade nas escolas e políticas de formação. Revista da ABEM, Porto Alegre, v. 12, p. 49-56, mar. 2005.

SCHUTZ, A. Fenomenologia e relações sociais. Organização e Introdução de Helmut R. Wagner. Rio de Janeiro: Zahar, 1979.

SILVA, N. F. da. A representação de música brasileira nos livros didáticos de música. Porto Alegre, 2002. Dissertação (Mestrado em Música), Programa de Pós-Graduação em Música, Instituto de Artes, Universidade Federal do Rio Grande do Sul.

SMIT, B. Teachers, local knowledge, and policy implementation: a qualitative policypractice inquiry. Education and Urban Society, vol. 37, n. 3, p. 292-306. May 2005. Disponível em: <http://eus.sagepub.com/cgi/content/abstract/37/3/292>. Acesso em: 15 mar. 2009.

SOUZA, J. Pesquisa e formação em educação musical. Revista da ABEM, n. 8, p. 7-10, mar. 2001.

. (Org). Livros de música para a escola: uma bibliografia comentada. Série Estudos ñ 3. Porto Alegre: PPG Música - UFRGS, 1997.

SOUZA, J.: DEL-BEN, L. Produção de material didático para/na formação de professores de música. In: ENCONTRO ANUAL DA ASSOCIAÇÃO BRASILEIRA DE EDUCAÇÃO MUSICAL. 16. Campo Grande, 2007. Anais... Campo Grande: Abem, 2007. 1 CD. 
SOUZA, J. et al. Produção de material didático em música: análise de resultados. In: ENCONTRO DE PESQUISA EM ARTE, 5., Montenegro, 2007. Anais... Montenegro: UERGS, 2007. p. 181-187. 1 CD.

. O que faz a música na escola? Concepções e vivências de professores do ensino fundamental. Série Estudos, Porto Alegre, v. 6, p. 3-130, 2002.

SWANWICK, K. A basis for music education. London: Nfer, 1979.

TACUCHIAN, R. Novos e velhos caminhos. ENCONTRO ANUAL DA ASSOCIAÇÃO BRASILEIRA DE EDUCAÇÃO MUSICAL, 1992. Anais... Rio de Janeiro: ABEM, 1992.. . In: ENCONTRO ANUAL DA ASSOCIAÇÃO BRASILEIRA DE EDUCAÇÃO MUSICAL, 1., 1992, Rio de Janeiro. Anais... Rio de Janeiro: ABEM, 1992. p. 4-11.

TARDIF, M. Saberes docentes e formação profissional. Petrópolis: Vozes, 2002.

WEAVER-HIGHTOWER, M. B. An ecology metaphor for educational policy analysis: a call to complexity. Educational Researcher, vol. 37, n. 3, p. 153-167, Apr. 2008. Disponível em: <http://edr.sagepub.com/cgi/content/abstract/37/3/153>. Acesso em: 15 mar. 2009.

E-mail: lucianadelben@uol.com.br

Artigo recebido e aprovado em 05 de abril de 2009 